${ }^{\circledR}$ Entomologica Fennica. 30.IV.1992

\title{
Field evidence of intra- and interspecific predation in rock-pool corixids (Heteroptera, Corixidae)
}

\author{
V. Ilmari Pajunen \& Irmeli Pajunen
}

Pajunen, V. I. \& Pajunen, I. 1992: Field evidence of intra- and interspecific predation in rock-pool corixids (Heteroptera, Corixidae). — Entomol. Fennica $3: 15-19$.

Small corixid larvae were introduced into a rock-pool containing large numbers of later developmental stages. High mortality of small larvae was observed. A considerable proportion of larval carcases recovered each had triangular holes on its upper surface. Similar holes are characteristic of carcases recovered in laboratory cannibalism experiments. The dimensions of the punctures in field and laboratory samples match closely. Predatory interactions between large and small rock-pool corixid larvae are thus common in field conditions.

V. Ilmari Pajunen, Division of Ecology, Department of Zoology, University of Helsinki, P. Rautatiekatu 13, SF-00100 Helsinki, Finland

Irmeli Pajunen, Department of Nutrition, University of Helsinki, SF-00710 Helsinki, Finland

\section{Introduction}

Cannibalism and interspecific predation between closely related species have been reported in several groups of arthropods (Fox 1975, Polis 1981, 1984) but opinions on their ecological significance seem to differ. In theory such attacks can act as a means of population limitation, but the effects are often difficult to measure directly in field conditions, and the relevance of laboratory experiments can be questioned. Thus, Brinkhurst (1966) suggested cannibalism to be important for population limitation in Gerris najas Degeer based on the correlation found between mortality rate of small larvae and number of larger larvae, as well as laboratory observations of cannibalism. Several later workers subsequently assumed cannibalism to be the main regulating factor in gerrids, but Spence (1986) suggested that its effects were minimized by habitat heterogeneity and spatial separation of age classes, dismissing cannibalism as a mortality factor of minor importance.

In studies on the rock-pool corixids Arctocorisa carinata (C. Sahlberg) and Callicorixa producta (Reuter), the situation is comparable. Early in the reproductive season mortality of larvae in rock-pools is low, but as the density of large larvae increases, mortality of the first larval stages rapidly increases (Pajunen 1977). This affects the recruitment to later developmental stages, and their density drops to a low level. Thus, after a certain time-lag, mortality of small larvae decreases, and their density again increases. Consequently, larval density fluctuates cyclically despite of potentially constant recruitment throughout the reproductive season. Cannibalism or superior competition by later developmental stages was suggested by Pajunen (1977), while Pajunen \& Ukkonen (1986) showed that intra- 
and interspecific predation occurred in the laboratory at larval densities equivalent to those in typical field conditions. Some interspecific differences were recorded, A. carinata being more efficient predator and less vulnerable as prey. The incidence of predation measured was sufficient to account for changes in the mortality of small larvae observed in rock-pools.

Doubts can, however, be expressed concerning the applicability of relatively simple laboratory experiments in field conditions. Even the extremely simple rock-pool environment is more complex than any experimental setup. Intra- and interspecific predation should be shown to be a significant mortality factor in rock-pools. Field experiments were arranged to provide the desired information.

\section{Material and methods}

First- and second-stage larvae of Callicorixa producta were obtained from laboratory cultures or collected from small rock-pools in which it was the dominant species. These were then introduced into a rock-pool containing high numbers of old larvae. The surface area of the rockpool was $4 \mathrm{~m}^{2}$, the bottom sediment consisting of $5-10 \mathrm{~cm}$ green detritus. Previous monitoring had shown that this population had progressed far in its density cycle and thus no 1st- and 2nd-stage larvae were found in samples taken prior to the experiment. The density of the bottom-living animals (chironomid larvae) was already relatively low, with large-sized Chironomus and Glyptotendipes larvae dominating. The density of adults and larvae of the dytiscid Potamonectes griseostriatus De Geer were very low. A total of 500 young larvae were introduced during a four day-period (22-25 July), one half of them in the 1st stage. On 25-28 July, larval skins and carcases were collected by netting both those lying on the surface and those in the actual body of water. The material was preserved in ethanol and inspected with the aid of a stereomicroscope. Incomplete skins (parts of thorax or abdomen missing) were discarded, as they probably represented moults prior to the experiment. Complete skins and carcases were identified as to stage and counted. In order not to damage the skins plastic pipettes were used in sorting.
In order to distinguish individuals killed by corixids, living 1st- and 2nd-stage larvae were confined in small aquaria with 5th-stage larvae of A. carinata. After $1 \mathrm{~d}$ the carcases were collected and preserved in ethanol. A sample of carcases as well as a sample from the rock-pool were compared with the aid of a SEM type JSEM820 (Jeol Co., Japan).

On 27 July the numbers of corixid larvae in the rock-pool were estimated by removal trapping. The field procedure was as given in Pajunen (1972). The estimates were calculated using the method of Zippin (1956).

\section{Results}

\subsection{Stage-specific numbers}

Population estimates were calculated separately for the 1st through 3rd stages and 4th through adult stages by pooling the respective data. The point estimates ( \pm standard errors) were as follows: small larvae: $283 \pm 71$, large larvae and adults: $583 \pm 175$. When the totals were divided according to proportions of stages captured, the numbers were:

$\begin{array}{lcccccc}\text { Stage } & 1 \text { st } & \text { 2nd } & \text { 3rd } & \text { 4th } & \text { 5th } & \text { Adult } \\ \text { Numbers } & 29 & 69 & 184 & 222 & 297 & 64\end{array}$

The total densities of earlier and of later developmental stages were thus $70 \mathrm{ind} / \mathrm{m}^{2}$ and 145 ind $/ \mathrm{m}^{2}$. Because during high population densities the duration of 1 st and 2 nd stages is 5-7 days, it can be assumed that all individuals in the 3rd stage were experimentally introduced individuals. Thus the introduced small larvae had in 4-5 days suffered a mortality of some $40 \%$.

Large larvae were not identified to species, but there appeared to be a preponderance of largesized larvae, suggesting that some $70 \%$ of larvae were A. carinata, the more efficient predator of small larvae in laboratory experiments (Pajunen \& Ukkonen 1986).

\subsection{Larval skins and dead individuals}

An earlier study, in which collection of skins of later larval stages was attempted, indicated that 
smaller skins were more difficult to recover. It is thus clear that exhaustive collecting was not possible, and samples were biased. The date of moulting or death could not be assessed.

The recently dead individuals and the cast skins were readily distinguishable, the latter having ecdysial sutures in the head and thorax open and broken tracheae clearly visible. In carcases of dead individuals sutures in head and thorax were closed. Two types of carcases were found. In the first the cuticle was undamaged, the abdomen was swollen, and internal organs at various stages of decomposition were discernible. In the second type the cuticle was pierced dorsally, usually in several places, the carcases were flattened, and the internal organs were almost totally dissolved, some reddish pigment often remaining in the head. Individuals of the first type were obviously not consumed by any predator, whereas individuals of the second type had been consumed by a predator with sucking mouthparts, which had used external digestion.

The carcases of larvae killed by corixids in the laboratory also had multiple punctures on their dorsal side and the internal organs were dissolved. In all cases the punctures were concentrated on thorax and head. Abdominal punctures were usually smaller; presumably the flattened abdomen precluded deeper penetration in small larvae. As dead larvae lie on their dorsal side, and the mouthparts of corixids are orientated ventrally, feeding had obviously started when the victims were still alive.

The punctures in all carcases were triangular, and when several were made close together, they all tended to have a similar orientation. Large irregular holes were also occasionally observed. These were presumably results of cuticular ruptures between the punctures. The length of the base of thoracic punctures and the distance between apex and base was measured in 6 carcases both from laboratory tests and field material (35 punctures per individual, with one individual having only a single puncture). In both groups the differences between carcases were significant (ANOVA, $P<0.01$ in all cases) suggesting that multiple punctures were made by a single predator. The range in mean base length was 40.7 $56.8 \mu \mathrm{m}$ in the laboratory material and $29.2-$ $54.4 \mu \mathrm{m}$ in the field material and the range in mean relative height $36.4-54.7 \%$ and 27.1 $57.0 \%$, respectively. One of the carcases in the field sample had smaller punctures than others (carcass D in Fig. 1), the difference being comparable to the size difference between the 4th and 5th stages of A. carinata. When this individual was omitted, no differences between the two samples were found, the mean base length and the relative height in the laboratory and field samples being $47.5 \pm 2.6 \mu \mathrm{m}$ and $45.9 \pm 3.3 \mu \mathrm{m}$, and $46.9 \pm 2.8 \%$ and $40.4 \pm 4.6 \%$, respectively. The carcases with punctures could thus be assumed to have been killed by corixids. In the rock-pool studied, no other predators using comparable feeding methods were present.

The numbers of different types found in the field material appear in Table 1. A comparison with estimated numbers shows that recovery rate increases with size, and thus no comparison between the successive larval stages is possible. On the other hand, no factor causing differences in recovery of the two types of dead individuals within a larval stage is known. The impact of corixid predation can thus be estimated, amounting to $73 \%$ of young larvae dead. The rate decreases slightly from the 1 st $(88 \%)$ to the 3 rd stage $(69 \%)$.

\section{Discussion}

Results indicate that small corixid larvae are readily preyed on in conditions typical of rockpools, and that intra- and interspecific predation can be an important mortality factor thus acting to limit population. The densities used are common in situations in which high mortality of small larvae is usually encountered (Pajunen

Table 1. Numbers (and percent) of different types of carcases and larval skins recovered.

\begin{tabular}{lrrrrrr}
\hline Stage & Killed & Dead & $\begin{array}{c}\text { Successfully } \\
\text { moulted }\end{array}$ & Total \\
\hline 1st & $23(58)$ & 3 & $(7)$ & $14(35)$ & 40 \\
2nd & $39(31)$ & 11 & $(8)$ & $77(61)$ & 127 \\
3rd & $36(32)$ & $16(14)$ & $59(54)$ & 111 \\
4th & $3(5)$ & 3 & $(5)$ & $48(90)$ & 54 \\
5th & 0 & $8(18)$ & $37(82)$ & 45 \\
\hline
\end{tabular}



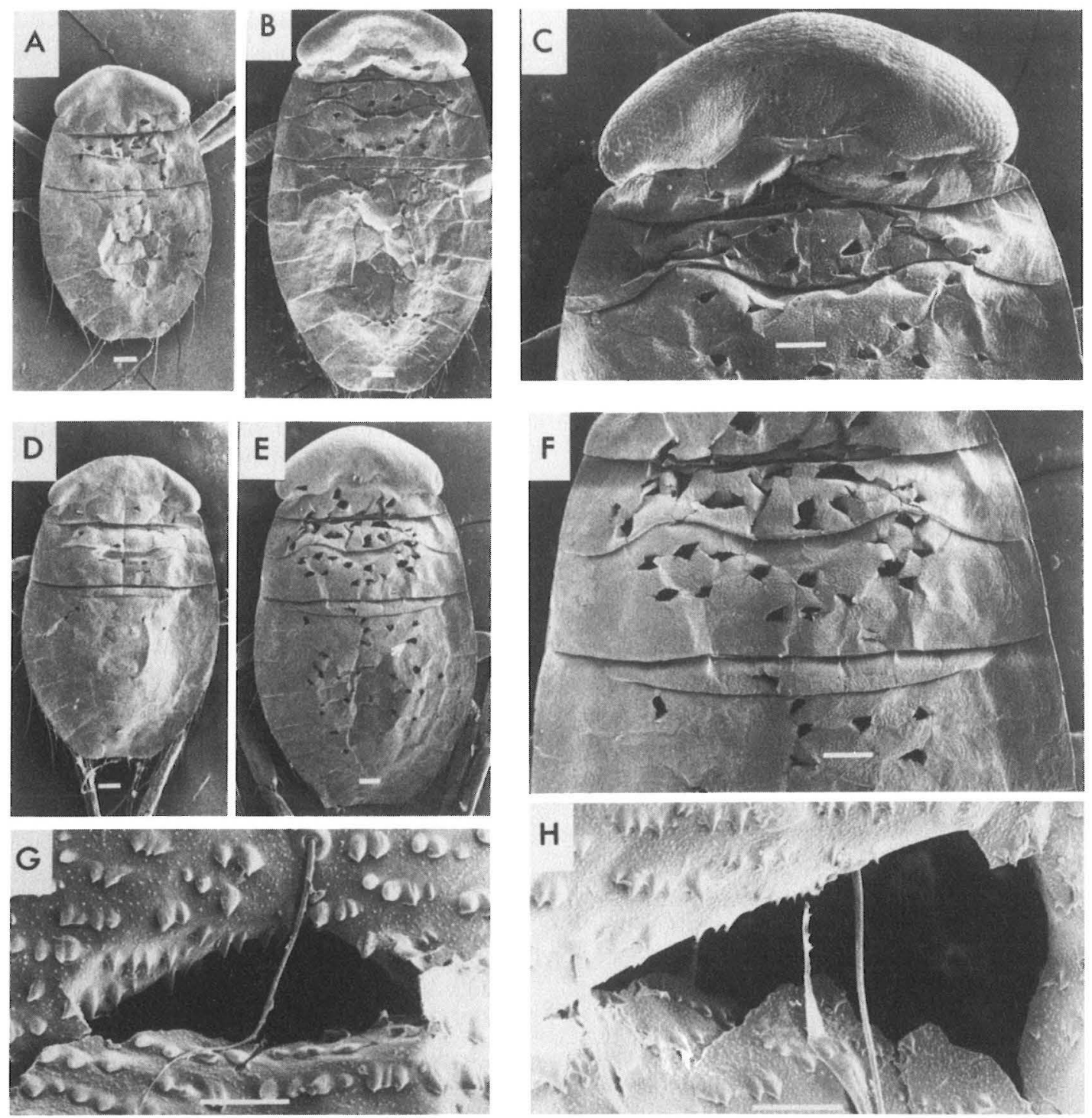

Fig. 1. Carcases of $C$. producta larvae. - A: 1st-stage larva form the laboratory experiment. B-C: 2nd-stage larva from the laboratory experiment. D: 1st-stage larva from rock-pool presumably killed by 4th-stage $A$. carinata larva. E-F: 2nd-stage larva from rock-pool killed by 5th-stage A. carinata larva. G-H: Detalis of punctures in D and $\mathrm{E}$, locations indicated by arrows. Scale bar $100 \mu \mathrm{m}$ for $\mathrm{A}-\mathrm{F}, 10 \mu \mathrm{m}$ for $\mathrm{G}$ and $\mathrm{H}$.

1977, 1986). The only difference from the natural system was that small larvae were introduced relatively late, when normally recruited small larvae already would have been eliminated, and thus the density of natural prey available was probably relatively low. When corixid populations attain high densities, prey densities decrease markedly (Pajunen \& Salmi 1991).
Spence (1986) suggested that in heterogeneous habitats predation-related factors limit gerrid populations before potential cannibalism becomes important. Comparable arguments can be used to pronounce cannibalism and interspecific predation important for density limitation in corixids. In rock-pools the habitat structure is simple. The bottom sediment is in most cases only a few $\mathrm{cm}$ 
thick, and no habitat stratification is possible. Smaller larvae have no refuge. In rock-pools the trophic structure is very simple, and in many cases corixids are top predators, tightly coupled with their principal prey populations (Pajunen \& Salmi 1991). In such situations, when other mortality factors do not act, cannibalism can be important.

Acknowledgements. We wish to thank the staff of the Department of Electron Microscopy, University of Helsinki, for help and advice in SEM investigations.

\section{References}

Brinkhurst, R. O. 1966: Population dynamics of the large pondscater Gerris najas Degeer (Hemiptera-Heteroptera). - J. Anim. Ecol. 35:13-25.

Fox, L. E. 1975: Cannibalism in natural populations. Ann. Rev. Ecol. Syst. 6:87-106.

Pajunen, V. I. 1972: Evaluation of a removal method for estimating the numbers of rock pool corixids. - Ann. Zool. Fennici 9:152-155.
- 1977: Population structure of rock pool corixids (Hemiptera, Corixidae) during the reproductive season. - Ann. Zool. Fennici 14:26-46.

- 1986: How to construct and use realistic physiological time scales: an analysis of mortality of rock-pool corixids (Hemiptera, Corixidae). - Oikos 47:239-250.

Pajunen, V. I. \& Salmi, J. 1991: The influence of corixids on the bottom fauna of rock-pools. - Hydrobiologia 222:77-84.

Pajunen, V. I. \& Ukkonen, M. 1987: Intra- and interspecific predation in rock-pool corixids (Hemiptera, Corixidae). - Ann. Zool. Fennici 24:295-304.

Polis, G. A. 1981: The evolution and dynamics of intraspecific predation. - Ann. Rev. Ecol. Syst. 12: 225-251.

- 1984: Intraspecific predation and "infant killing" among invertebrates. - In: Hausfater, G. \& Hrdy, S. B. (ed.), Infanticide: comparative and evolutionary perspectives: 87-104. Hawthorne.

Spence, J. R. 1986: Relative inpacts of mortality factors in field populations of the waterstrider Gerris buenoi Kirkaldy (Heteroptera: Gerridae). — Oecologia (Berlin) 70:68-76.

Zippin, C. 1956: The removal method of population numbers. - J. Wildlife Managem. 22:82-90. 